\title{
INTERNAL FIT EVALUATION OF ALL CERAMIC RESTORATION FABRICATED BY TWO CAD/CAM MILLING SYSTEMS USING CONE BEAM CT (CBCT)
}

\author{
Hesham A. Aboudorra *, Haitham Amr ${ }^{* *}$, Ahmed El zohairy***, \\ Amir Hafez ${ }^{* * * *}$ and Ahmed A. Hassan ${ }^{* * * * *}$
}

\begin{abstract}
Objective: to evaluate the internal fit of all ceramic restoration fabricated by two CAD/CAM milling systems using cone beam CT (CBCT).

Materials and methods: A total number of 20 all ceramic restorations were manufactured in this study, and were equally divided into two main groups $(n=10)$ according to the type of CAD/ CAM system used in the manufacturing process. Group I (Cerec in-lab system) and group II (Everest system) using the e.max CAD blocks specified for each milling system. specially designed stainless steel die was manufactured with specified dimensions. The die was scanned, the all ceramic restoration was designed and milled according to the different CAD/CAM milling systems used, and then crystallization procedure was carried. Duplication of the metal die into epoxy resin dies was performed and the final all ceramic restorations were the placed over the epoxy resin dies and examined for internal gap measurement using cone beam computed tomography (CBCT). Numerical data were explored for normality using Kolmogorov-Smirnov test of normality. Normally distributed (parametric data), were presented as mean, standard deviation and were compared between groups using independent $t$ test. Non-parametric data were compared between groups using Mann Whiney U test. Gingival, axial and occlusal segments were compared using Friedman test and Wilcoxon signed rank test. The significance level was set at $p<0.05$. Statistical analysis was performed with SPSS 18.0 for windows.
\end{abstract}

Results: Comparison between groups using the mean of the 3 successive sections in buccolingual section revealed that a higher mean value was recorded in Cerec for each of the gingival, axial and occlusal segments, with no statistically significant difference between groups $(p=0.138$, $\mathrm{p}=0.06, \mathrm{p}=0.276$ respectively), while in mesio distal section a higher mean value was recorded in Cerec in the gingival and axial segments, with no significant difference between groups $(p=0.296$,

\footnotetext{
* DDS of Fixed Prosthodontic, Faculty of Dentistry, Alazhar University

** Lecturer of Fixed Prosthodontic, Faculty of Dentistry, Fayoum University

*** Ass. Professor of Conservative Dentistry, Faculty of Dentistry, Cairo University

**** Lecturer of Conservative Dentistry, Faculty of Dentistry, Cairo University

*****Ass. Lecturer of Oral Radiology, Faculty of Dentistry, Fayoum University
} 
$\mathrm{p}=0.568$ respectively). In the occlusal section, a higher mean value was recorded in Kavo Everest, with no statistically significant difference between groups $(\mathrm{p}=0.734)$. Comparison of gingival, axial and occlusal segments within the same group in bucco-lingual section revealed that in Kavo Everest group, a significantly higher mean value was recorded in occlusal segment in comparison to the gingival and axial segments $(\mathrm{p}=0.001)$. In cerec group, a significantly higher mean value was recorded in occlusal segment in comparison to the gingival and axial segments $(p=0.00)$, while in mesio distal section , in Kavo Everest group, a significantly higher mean value was recorded in occlusal segment in comparison to the gingival and axial segments $(\mathrm{p}=0.00)$. In Cerec group, a significantly higher mean value was recorded in occlusal segment in comparison to the gingival and axial segments $(\mathrm{p}=0.00)$.

Conclusion: The technique of CAD/CAM milling system has affected the internal fit of CAD/ CAM all-ceramic restorations.

Key words: internal fit, all ceramic restoration, e-max CAD,CAD/CAM milling system, Cerec in-lab system, Everest, internal gap measurement, cone beam CT.

\section{INTRODUCTION}

The recently introduced $\mathrm{CAD} / \mathrm{CAM}$ all ceramic restorations have gained a considerable popularity because of their natural appearance, acceptable structural durability and outstanding biocompatibility. An important factor that ensures the long-term success of indirect esthetic restorations is the precision of the margins. Inadequate adaptation of the restoration may be a detrimental factor for the tooth and the periodontal supporting tissue..$^{(1-5)}$

Dental literature and reported clinical data, though are not sufficient enough, but revealed the inherent brittleness of ceramics as a material which renders all ceramic restorations always suffering some risk of fracture. Dental ceramics can fracture through growth of microscopic surface flaws that form during processing or from surface impact during service. Different restorative dental ceramic materials have been recently introduced to improve resistance to crack propagation. To prevent all ceramic restoration fracture, it was found that is not only required to use as strong a material as possible, but also to fabricate the all ceramic restorations with the best fit possible..$^{(3-9)}$

There were several factors that greatly affect the precision of all-ceramic restorations, such as restorative materials, manufacturing procedures, individual characteristics of the restorations or fixed prosthesis (e.g. framework configuration, span length) as well as cementation techniques. Also the effect of veneering and influence of aging are very critical. Several studies investigated the maximum clinically acceptable marginal gap width and different values were proposed in the literature according to the type of restoration. ${ }^{(6-7)}$ The studies showed clinically acceptable accuracy of fit. Specifically, maximum marginal openings ranging between $40-90 \mu \mathrm{m}$ for CAD-CAM restorations. Nevertheless, a wide range of marginal opening values was described in the literature due to restoration type and location. ${ }^{(8-13)}$ Furthermore, as with CAD-CAM systems, the accuracy of fit may be influenced by scanning procedures, software design, milling procedures and shrinkage compensation. ${ }^{(14-19)}$

The cone beam computed tomography (CBCT) is nowadays considered the most updated investigational approach that allows for a noninvasive evaluation method of the internal gap measurement of all ceramic restoration. Therefore, the aim of the present in vitro study was to assess the internal gap of all ceramic restorations, produced with different manufacturing procedures using cone 
beam computed tomography (CBCT) to determine their internal fit accuracy. ${ }^{(19-23)}$

The following null hypothesis was tested: there is no difference in accuracy of internal fit among the restorations produced with different $\mathrm{CAD} / \mathrm{CAM}$ milling system.

\section{MATERIALS AND METHODS}

A total number of 20 all ceramic restorations were manufactured in this study, and were equally divided into two main groups $(\mathrm{n}=10)$ according to the type of CAD/CAM system used in the manufacturing process. Group I (Cerec in-lab system) and group II (Everest system) using the e.max CAD blocks specified for each milling system as shown in (Table 1).

\section{Die Construction:}

For the purpose of standardization, a specially designed stainless steel die was manufactured using a lathe milling machine. The die was prepared with the approximate dimensions of an all-ceramic crown restoration preparation on a mandibular second molar, with a cervical diameter of $10 \mathrm{~mm}$, $6 \mathrm{~mm}$ height, 6 degree occlusal convergence and the occlusal surface was prepared with two sloping surfaces, one of which was slightly beveled, the preparation was finished with a $1 \mathrm{~mm}$ thickness round shoulder finish line.. This anatomical profile was given to the die to prevent rotation of the all ceramic restorations on the die, and also to assure the exact reproducibility of placement of the all ceramic restorations over the die.

\section{All- ceramic restorations construction:}

\section{Cerec In-Lab CAD/CAM system all ceramic resto- rations (figure 1)}

Step 1: Scanning of the die.

A new restoration was created in the Cerec inlab software version 3.60 (Sirona Dental Systems GmbH, D-64625 Bensheim, Germany), restoration data were entered in the window of the in-lab user interface. The die was then prepared by spraying it with a light reflecting anti-glare spray "Cerec optispray", and then was scanned using in-lab extra oral scanner "inEos". The in-lab software then uses that image for transforming it into a 3-D virtual model.

Step 2: Designing the all ceramic restorations on the software.

The 3-D virtual model displayed on the design window was then used to design the restoration with the help of the software given tools. The setting for the machining of all ceramic restorations for occlusal and lateral wall-thickness was entered to be $1.5 \mathrm{~mm}$ and with a $40 \mu \mathrm{m}$ cement space, and then the virtual all ceramic restorations were built according to the lee culp anatomy selected shape by using the software tools in the design windows box and the cut tool, which can take a segmental cut through any plane of the 3-D model die and all ceramic restoration.

Step 3: Milling process.

The in-lab MC XL milling machine was then activated and the e.max CAD block was used to mill

Table (1) The materials used in this study, composition and manufacturer:

\begin{tabular}{|l|l|l|l|}
\hline No. & Materials & Composition & Manufacturer \\
\hline & $\begin{array}{l}\text { e.max CAD blocks for } \\
\text { Cerec in-lab }\end{array}$ & Lithium disilicate glass ceramic & $\begin{array}{l}\text { Ivoclar Vivadent AG,FL-9494 Schaan/ } \\
\text { Liechtenstein Germany }\end{array}$ \\
\hline $\begin{array}{l}\text { e.max CAD blocks for } \\
\text { Everest }\end{array}$ & Lithium disilicate glass ceramic & $\begin{array}{l}\text { Ivoclar Vivadent AG,FL-9494 Schaan/ } \\
\text { Liechtenstein Germany }\end{array}$ \\
\hline
\end{tabular}


the all ceramic restoration from e-max CAD blocks. For the purpose of standardization, the milling process was repeated for all the blocks with the exact same milling preview design saved in the software to produce identical all ceramic restorations.

Step 4: Crystallization process.

The blue un-crystallized milled restorations were trimmed carefully using diamond abrasives at very low speed, to remove excess material at the site of the connection with the ceramic block. Then were inserted into the furnace "Programat P300" to start the combination crystallization/glaze firing cycle according to firing parameters instructed by the manufacturer and already preset in the furnace software.

\section{Everest CAD/CAM system all ceramic restorations (figure 2)}

Step 1: Scanning process of the die

A new restoration was created in the Everest Scan Control user interface software version 3.X (Kavo Dental GmbH Bismarckring 39 D-88400 Biberach/Riß Germany). The die was then prepared by spraying it with a 3-D laser scanning antiglare spray (Helling GmbH. Spökerdamm 2 D-25436 Heidgraben, Germany.), and then was scanned using the Everest system extra oral scanner "Everest scan pro" (Kavo Dental GmbH Bismarckring 39 D-88400 Biberach/Riß Germany). The measuring plate rotates and tilts during the scanning process and 15 different projections sequence patterns are taken in different positions with the built in highend CCD camera with a resolution of 1392 x 1040 pixels.

For the purpose of standardization, a modeling scan was performed by which the die was first scanned and then a model (all ceramic restoration sample from group I) was seated on the die and another scan was preformed of the die and all ceramic restoration together to be able to replicate the same exact shape and dimensions of the in-lab all ceramic restorations.
Step 2: The surface process.

When the modeling scan procedure was completed, the surface process started and the data of the scanned model is converted into a 3-D virtual model at a ratio of 1:1 on the Everest Scan Control user interface.

Step 3: The CAD process.

In the design preview the cement space was adjusted also to $40 \mu \mathrm{m}$, and then the all ceramic restoration was designed on the 3-D virtual model guided by the data obtained from the double scan technique.

Step 4: The CAM process.

After the design process was completed, the CAM step was started, in which the job data was sent to the Everest system milling unit (Engine) and its associated control computer unit. The e.max CAD blocks were fixed to the gripping yoke of the milling machines by means of stainless steel metal inserts, the blocks were embedded in the inserts by using Everest Universal Inplast. After that the milling machine started to manufacture the cavity side followed by occlusal side or external side.

Step 5: The crystallization process.

All ceramic restorations were then removed from the inserts of the milling machine and cleaned with a steam jet prior to crystallization. Crystallization procedure was carried out exactly the same as mentioned before with e.max CAD all ceramic restorations manufactured from the in-lab system.

\section{Duplication of the metal die into epoxy resin dies:}

Epoxy resin die material (epoxy-die, ivoclar AG) was prepared accoding to manufacturer's instructions and then poured into silicon duplicate of the metal die. The epoxy die were allowed to completely harden for 12 hours, then removed and checked for complete filling, presence of air bubbles and accurate margin reproduction using magnifying 
lens. The final all ceramic restorations were then placed over the epoxy resin dies and examined for internal fit using cone beam computed tomography (CBCT)

\section{Internal gap measurement:}

\section{Settings of Cone Beam Computed Tomography $(C B C T)$ :}

CBCT images were acquired using a Next Generation i-CAT scanner (Imaging Sciences International, Inc., Hatfield, USA). A scout (preview) was obtained and adjustments were made to ensure that the all samples were correctly aligned in the scanner according to adjustment light beam before acquisition. The machine is supplied with Amorphous Silicon Flat Panel Sensor with Cesium Iodide (CsI) scintillator, $0.5 \mathrm{~mm}$ focal spot size, 14 Bit gray scale resolution, and operating at the following protocol for all the scans of the study:

$\begin{array}{ll}\text { Tube voltage } & 120 \mathrm{kVp} \\ \text { Milliampere } & 37.07 \mathrm{mAs} \\ \text { Voxel size } & 0.125 \mathrm{~mm} \\ \text { Scanning time } & 26.9 \text { seconds } \\ \text { Field of view } & 4 \mathrm{~cm} \text { Height } * 16 \mathrm{~cm} \text { Diameter }\end{array}$

After acquisition, data were exported and transferred in DICOM format and downloaded via a Compact Disk (CD) to a personal computer for linear and density measurement, where, Invivo Dental software (version 5.4; Anatomage, San Jose, CA, USA) was utilized.

\section{Measuring the internal gaps:}

At the software interface, Section module was the one of choice to obtain all measurements at, where all data were presented at axial, coronal and sagittal perspectives. For all measurements fixed window level and window width was used to standardize the viewing condition. For each all ceramic restoration, the reference lines were set at the three views to intersect at the center of the all ceramic restoration, and parallel to its long axis of the dye as well. The points were labeled in the bucco-lingual (Y-axis) and mesio-distal (X-axis) orientation. The reference bucco-lingual section was taken passing through the buccal and palatal cusp tips of the all ceramic restoration restoration (Y-axis); additional cross-sections were utilized at the middle of the restoration using the same orientation at $1 \mathrm{~mm}$ interval. The reference mesiodistal section was taken passing through the central groove of the restoration (X-axis); additional crosssections were obtained bilaterally at $1 \mathrm{~mm}$ intervals for a total of 3 mesio-distal sections. The following points were assigned to record the gap between the restoration and the die:(gingival, axial and occlusal). The measurements of the internal gap were made for each all ceramic restoration at these points at three successive bucco-lingual sections, and three successive mesio-distal sections as well. The results were recorded, tabulated for statistical analysis.

\section{Statistical analysis}

Numerical data were explored for normality using Kolmogorov-Smirnov test of normality. Normally distributed (parametric data), were presented as mean, standard deviation and were compared between groups using independent $t$ test. Non-parametric data were compared between groups using Mann Whiney $U$ test. Gingival, axial and occlusal segments were compared using Friedman test and Wilcoxon signed rank test. The significance level was set at $p<0.05$. Statistical analysis was performed with SPSS 18.0 (Statistical Package for Scientific Studies, SPSS, Inc., Chicago, IL, USA) for Windows. 


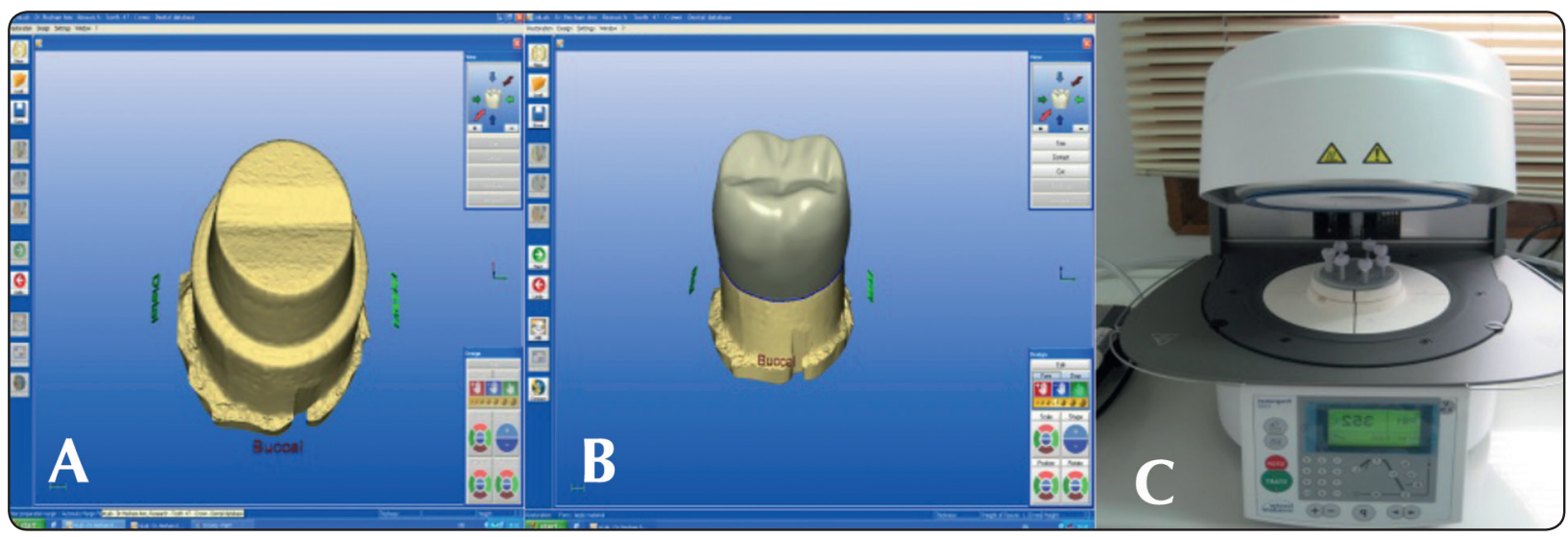

Fig. (1): Steps of construction of Cerec In-Lab CAD/CAM system all ceramic restorations. A: scanning of the die, B: designing of the restoration, C: crystallization of the restoration.

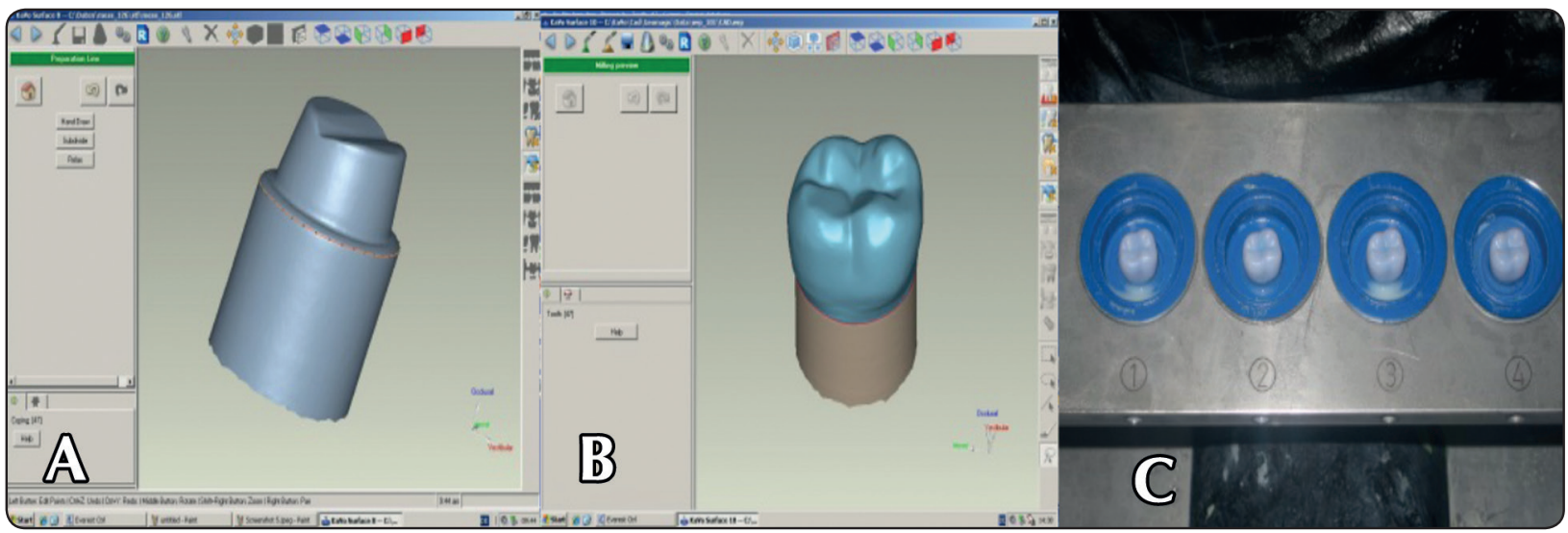

Fig. (2): Steps of construction of Everest CAD/CAM system all ceramic restorations. A: scanning of the die, B: designing of the restoration, C: crystallization of the restoration.

\section{RESULTS}

\section{Detailed comparison between groups for each of the 3 successive sections}

\section{a-Bucco-lingual section}

In $\mathrm{C} 1$, a higher mean value was recorded in Cerec for each of the gingival, axial and occlusal segments, with no statistically significant difference between groups $(\mathrm{p}=0.94, \mathrm{p}=0.19, \mathrm{p}=0.32$ respectively), (Table2)

In $\mathrm{C} 2$, a higher mean value was recorded in Cerec in the gingival segment, with no significant difference between groups $(p=0.52)$. In the axial section, a higher mean value was recorded in Kavo
Everest, with statistically significant difference between groups ( $\mathrm{p}=0.0061$ ). In the occlusal segment, a higher mean value was recorded in Cerec, with statistically significant difference between groups $(\mathrm{p}=0.00)($ Table2)

In $\mathrm{C} 3$, a higher mean value was recorded in Cerec in the gingival segment, with no significant difference between groups $(\mathrm{p}=0.064)$. In the axial section, a higher mean value was recorded in Cerec, with statistically significant difference between groups $(\mathrm{p}=0.0048)$. In the occlusal segment, a higher mean value was recorded in Kavo Everest, with no statistically significant difference between groups $(\mathrm{p}=0.53)$ (Table2) 


\section{b-Mesio distal section}

In S1, a higher mean value was recorded in Kavo Everest for the gingival segment, with no significant difference $(\mathrm{p}=0.73)$. A higher mean value was recorded in Cerec in the axial segment, with no statistically significant difference between groups ( $\mathrm{p}=0.235$ ). In the occlusal segment, a higher mean value was recorded in Kavo Everest, with a significant difference $(\mathrm{p}=0.003)$, (Table 3$)$

In S2, a higher mean value was recorded in Cerec in the gingival segment, with no significant difference between groups $(p=0.184)$. In the axial section, a higher mean value was recorded in Kavo
Everest, with statistically significant difference between groups ( $\mathrm{p}=0.0007)$. In the occlusal segment, a higher mean value was recorded in Cerec, with no statistically significant difference between groups $(\mathrm{p}=0.797)$ (Table 3)

In S3, a higher mean value was recorded in Kavo Everest in the gingival segment, with significant difference between groups $(\mathrm{p}=0.00)$. In the axial section, a higher mean value was recorded in Cerec, with statistically significant difference between groups $(\mathrm{p}=0.008)$. In the occlusal segment, a higher mean value was recorded in Kavo Everest, with statistically significant difference between groups $(\mathrm{p}=0.00)$ (Table 3)

TABLE (2) Comparison between Kavo Everest and Cerec groups for each of the 3 successive buccolingual sections (independent $\mathrm{t}$ test)

\begin{tabular}{|c|c|c|c|c|c|c|c|c|c|c|}
\hline & & \multicolumn{9}{|c|}{ Bucco-lingual section } \\
\hline & & \multicolumn{3}{|c|}{$\mathrm{C1}$} & \multicolumn{3}{|c|}{$\mathrm{C2}$} & \multicolumn{3}{|c|}{ C3 } \\
\hline & & Ging. & axial & Occ. & Ging. & axial & Occ. & Ging. & axial & Occ. \\
\hline \multirow{2}{*}{$\begin{array}{c}\text { Kavo } \\
\text { Everest }\end{array}$} & Mean & 0.087 & 0.054 & 0.150 & 0.067 & 0.058 & 0.192 & 0.055 & 0.014 & 0.277 \\
\hline & SD & 0.022 & 0.023 & 0.073 & 0.021 & 0.029 & 0.081 & 0.023 & 0.011 & 0.155 \\
\hline \multirow[t]{2}{*}{ Cerec } & Mean & 0.088 & 0.070 & 0.181 & 0.075 & 0.025 & 0.218 & 0.104 & 0.039 & 0.238 \\
\hline & SD & 0.043 & 0.029 & 0.063 & 0.032 & 0.017 & 0.034 & 0.075 & 0.022 & 0.117 \\
\hline \multirow{2}{*}{$\begin{array}{l}\text { Intergroup } \\
\text { comparisons }\end{array}$} & $\mathbf{t}$ & 0.07 & 1.37 & 1.02 & 0.66 & 3.1 & 37 & 1.98 & 3.21 & 0.64 \\
\hline & $\mathbf{P}$ & $0.94 \mathrm{~ns}$ & $0.19 \mathrm{~ns}$ & $0.32 \mathrm{~ns}$ & $0.52 \mathrm{~ns}$ & $0.0061 *$ & $0.00 *$ & $0.064 \mathrm{~ns}$ & $0.0048^{*}$ & $0.53 \mathrm{~ns}$ \\
\hline
\end{tabular}

Significance level $p<0.05$, *significant, $n s=n o n$-significant

TABLE (3) Comparison between Kavo Everest and Cerec groups for each of the 3 successive mesio-distal sections (independent $\mathrm{t}$ test)

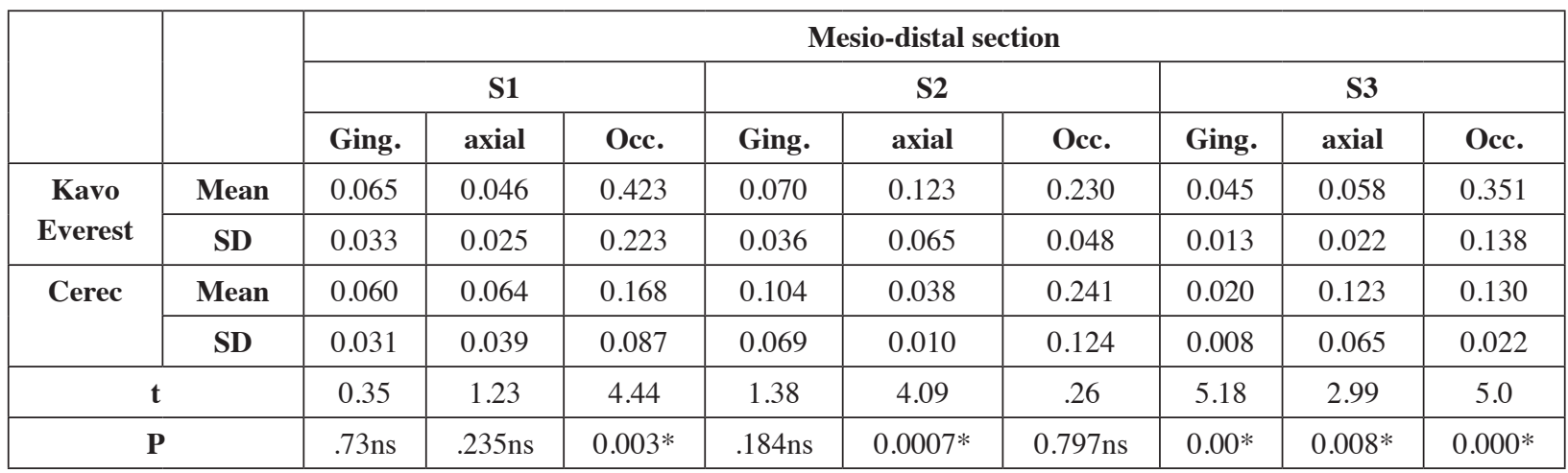

Significance level $p<0.05$, *significant, $n s=n o n-$ significant 
II-Comparison between groups using the mean of the 3 successive sections

\section{a- Bucco-lingual section}

A higher mean value was recorded in Cerec for each of the gingival, axial and occlusal segments, with no statistically significant difference between groups ( $\mathrm{p}=0.138, \mathrm{p}=0.06, \mathrm{p}=0.276$ respectively), (Table 4)

\section{b-Mesio distal section}

A higher mean value was recorded in Cerec in the gingival and axial segments, with no significant difference between groups $(\mathrm{p}=0.296, \mathrm{p}=0.568$ respectively). In the occlusal section, a higher mean value was recorded in Kavo Everest, with no statistically significant difference between groups $(\mathrm{p}=0.734)$, (Table4)
III-Comparison of gingival, axial and occlusal segments within the same group

\section{a-Bucco-lingual section}

In Kavo Everest group, a significantly higher mean value was recorded in occlusal segment in comparison to the gingival and axial segments $(\mathrm{p}=0.001)$. In cerec group, a significantly higher mean value was recorded in occlusal segment in comparison to the gingival and axial segments $(\mathrm{p}=0.00)$, (Table 5, Fig.3)

\section{b-Mesio distal section}

In Kavo Everest group, a significantly higher mean value was recorded in occlusal segment in comparison to the gingival and axial segments $(\mathrm{p}=0.00)$. In Cerec group, a significantly higher mean value was recorded in occlusal segment in comparison to the gingival and axial segments $(\mathrm{p}=0.00)$, (Table 5, Fig.3)

TABLE (4) Comparison between Kavo Everest and Cerec groups (Mann Whitney U test)

\begin{tabular}{|c|c|c|c|c|c|c|c|}
\hline & & & Mean & Std. Dev & $\begin{array}{c}\text { Std. Error } \\
\text { Mean }\end{array}$ & Mean difference & $\mathrm{P}$ \\
\hline \multirow{6}{*}{ Coronal } & \multirow{2}{*}{ Gingival } & Kavo Everest & .073 & .069 & .012 & -.03 & $.138 \mathrm{~ns}$ \\
\hline & & Cerec & .102 & .090 & .013 & & \\
\hline & \multirow{2}{*}{ Axial } & Kavo Everest & .036 & .048 & .013 & -.05 & $.06 \mathrm{~ns}$ \\
\hline & & Cerec & .087 & .099 & .021 & & \\
\hline & \multirow{2}{*}{ Occlusal } & Kavo Everest & .216 & .136 & .024 & -.02 & $.276 \mathrm{~ns}$ \\
\hline & & Cerec & .240 & .095 & .015 & & \\
\hline \multirow{6}{*}{ Sagittal } & \multirow{2}{*}{ Gingival } & Kavo Everest & .067 & .072 & .012 & -.01 & $.296 \mathrm{~ns}$ \\
\hline & & Cerec & .081 & .079 & .012 & & \\
\hline & \multirow{2}{*}{ Axial } & Kavo Everest & .085 & .087 & .022 & -.03 & $.568 \mathrm{~ns}$ \\
\hline & & Cerec & .114 & .141 & .028 & & \\
\hline & \multirow{2}{*}{ Occlusal } & Kavo Everest & .320 & .252 & .045 & .06 & $.734 \mathrm{~ns}$ \\
\hline & & Cerec & .261 & .147 & .022 & & \\
\hline
\end{tabular}

Significance level $p<0.05$, *significant, $n s=n o n-$ significant 
TABLE (5) Comparison of gingival, axial and occlusal segments within the same group (Friedman test)

\begin{tabular}{|c|c|c|c|c|c|}
\hline & & & Mean & SD & $\mathrm{P}$ \\
\hline \multirow[t]{6}{*}{ Coronal } & \multirow{3}{*}{ Kavo Everset } & Gingival & $.073^{\mathrm{b}}$ & .069 & \multirow[t]{3}{*}{$0.001 *$} \\
\hline & & Axial & $.036^{\mathrm{b}}$ & .048 & \\
\hline & & Occlusal & $.216^{\mathrm{a}}$ & .136 & \\
\hline & \multirow[t]{3}{*}{ Cerec } & Gingival & $.102^{\mathrm{b}}$ & .090 & \multirow[t]{3}{*}{$0.00 *$} \\
\hline & & Axial & $.087^{\mathrm{b}}$ & .099 & \\
\hline & & Occlusal & $.240^{\mathrm{a}}$ & .095 & \\
\hline \multirow[t]{6}{*}{ Sagittal } & \multirow[t]{3}{*}{ Kavo Everset } & Gingival & $.067^{\mathrm{b}}$ & .072 & \multirow[t]{3}{*}{$0.00 *$} \\
\hline & & Axial & $.085^{\mathrm{b}}$ & .087 & \\
\hline & & Occlusal & $.320^{\mathrm{a}}$ & .252 & \\
\hline & \multirow[t]{3}{*}{ Cerec } & Gingival & $.081^{\mathrm{b}}$ & .079 & \multirow[t]{3}{*}{$0.00 *$} \\
\hline & & Axial & $.114^{\mathrm{b}}$ & .141 & \\
\hline & & Occlusal & $.261^{\mathrm{a}}$ & .147 & \\
\hline
\end{tabular}

Significance level $p<0.05$, *significant, $n s=n o n$-significant Wilcoxon signed rank test: within the same comparison, means sharing the same superscript letter are not significantly different

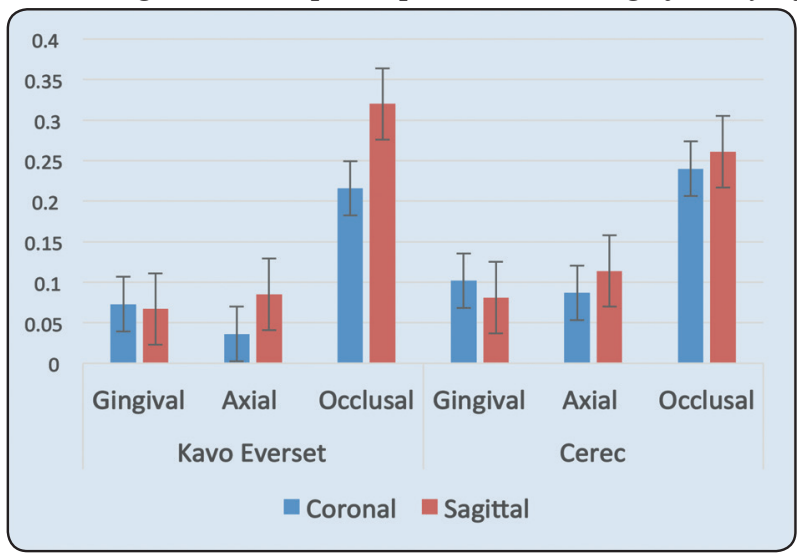

Fig. (3) Bar chart showing mean values of Kavo Everest and Cerec groups in coronal and sagittal sections

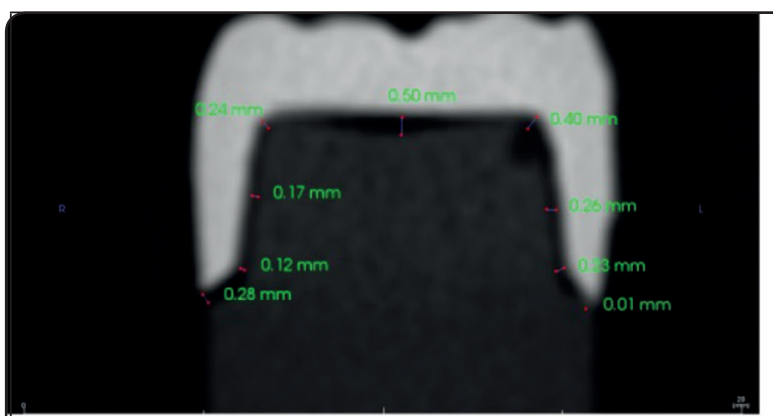

Cerec (mesio distal section)

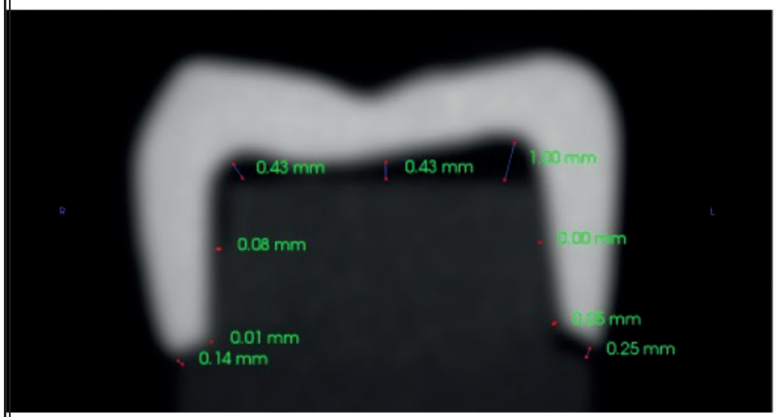

Everest (mesio distal section)

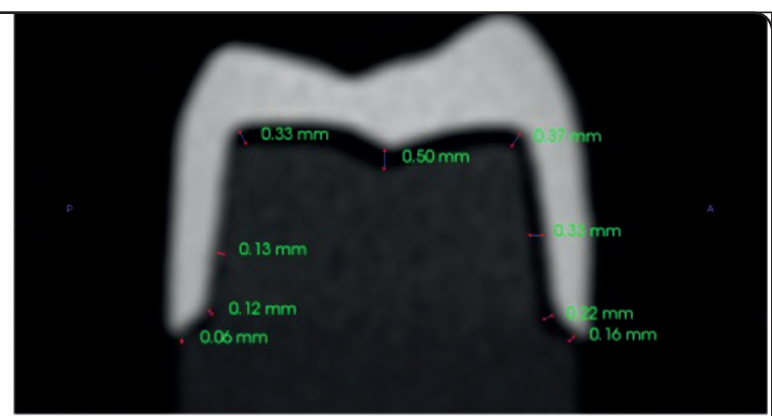

Cerec (bucco lingual section)

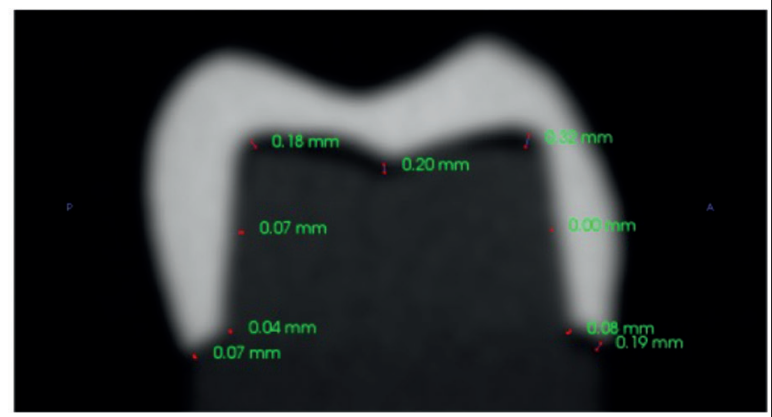

Everest (bucco lingual section)

Fig. (4) The measurements of internal gap between the all ceramic restoration and the dye :( gingival, axial and occlusal) in Cerec system and Everest system using CBCT 


\section{DISCUSSION}

The main interest of the present research was directed towards the in vitro evaluation of the internal fit of Lithium disilicate IPS e.max CAD all ceramic restorations as one of the most recently ceramic materials introduced to the market, and also evaluating the effect of the manufacturing process on this material, by using two different techniques of CAD/CAM manufacturing systems, the Everest system and the Cerec in-lab system. In this study the internal fit evaluation and gap measurement were performed using cone beam computed tomography (CBCT)

The in-vitro study is supposed however to offer standardized conditions with respect to the preparation design, impression technique or the experimental performance leading to assessments that may be closer to reality. Moreover, the internal fit and gap measurement using CBCT provide accurate analysis without subjecting the patients to the hazards of radiation. Also in contrast to the in vivo studies, the in vitro results should be viewed cautiously because of the testing limitations which cannot reflect exactly the clinical situations, but it might be beneficial to provide valuable clues and guidelines for the clinical applications..$^{(14)}$

A metallic stainless-steel master die was used in this study in substitution to natural tooth. Natural teeth present great variation considering the age, individual structures and time of storage, making the standardization of the tests very difficult. ${ }^{(6-9)}$ The advantages of the metal die include the easy reproduction achieving, the few present variables, standardized preparation and lack of wear during the manufacturing process and testing procedures, which helps in reducing as much as possible clinical faults and disturbing parameters and making of all samples up in a same initial situation, to standardize all manufacturing and testing procedures. ${ }^{(6-9)}$

The stainless steel die was constructed from stainless steel cylinder using a lathe milling machine, to have a conical profile, identical to an all-ceramic crown preparation on a mandibular second molar, with six millimeters height and with six degree of taper converging occlusally, and a twelve degree total convergence angle demonstrated the best internal fit and a highest retention for ceramic all ceramic restorations. ${ }^{(6-9)}$ It was also prepared with a one millimeters thickness radial (rounded) shoulder margin around the base of the die which was selected to meet the requirements for all-ceramic preparations used in this study. An anatomical profile was given to the die to approximate the size of a lower second molar tooth preparation and to prevent rotation of the all ceramic restoration samples on the dies, and also to assure the exact reproducibility of placement of the all ceramic restoration samples over the dies.

In order to perform detailed examination of the internal fit of different all ceramic restoration (either onlays, overlays or full coverage restorations) at different aspect of tooth preparation (gingival, axial and occlusal preparation), an all ceramic crown-shaped restorations were selected in this study as it will provide the data required for different preparation aspects. Furthermore, this all ceramic crown-shaped restorations were used because it has been reported that these may allow the restorations to behave in a manner that potentially represents the clinical situation. The setting for the machining of all ceramic crown restorations for occlusal and lateral wall-thickness was entered to be $1.5 \mathrm{~mm}$ which is known as a common design feature for all ceramic restorations according to the manufacturers' directions. $^{(21)}$

For purpose of standardization, identical samples were fabricated by the repetitive machining of the same design for each type of block. Also ceramic crown manufactured from the Cerec-inLab system was used in the double scan process of the Everest scan to manufacture samples of the exact dimensions and occlusal anatomy.

Another point of relevance is the aspect that concerns to the cementing of the samples. 
Some authors believe that the most important inadaptability is the one that occurs in vivo, when the all ceramic restorations are already cemented. ${ }^{(8-9)}$ Other authors believe that when samples are cemented it loses the precision of the primary adaptation, allowing the influence of the cement type, viscosity and cementation techniques to be a variable in the outcome results. They also approved that on comparing samples construction techniques and systems, cementation should not be used to minimize the variables as possible..$^{(18-23)}$

Although various protocols have been proposed to analyze marginal precision, no general guideline exists on how to perform gap measurements. ${ }^{(9-10)}$ Two significant internal and external precise methods are used to analyze marginal fit of restorations; studies investigating the internal marginal fit are mostly based on measurements of sectioned teeth. Although extremely accurate, these measurements result in the destruction of the restoration and consequently are of little use in clinical practice. (23) Other authors have used cross-sectional measurements with an impression material instead of a luting cement. This type of in vitro evaluation has inherent errors, such as a cut being oblique and resulting in the introduction of error into the measurement. ${ }^{(9)}$ Recently, an innovative method for evaluation of the internal three-dimensional fit of all ceramic restorations was developed, based on the registration of point clouds of duplicate gypsum dies on a CAD surface model that was identical to the metal master die. The results were shown to be suitable for this purpose. Other researchers used the scan electron microscope (SEM) method to quantitatively measure the marginal fit of all -ceramic restorations. ${ }^{(9-10,18)}$

Recently several studies reported that there is no agreement regarding the precision of fit of different crown systems because of differences in experimental protocols and testing approaches; although the direct view technique was the most common research method, the use of at least 50 measurements per specimen and the combination with micro-CT analysis should carry out more reliable results. ${ }^{(18-23)}$ Likewise, another study pointed out that the current state of the literature does not allow for a detailed comparison of different restorative systems in terms of marginal fit and the use of micro-CT should be recommended. ${ }^{(19)}$

Assessment of the internal gap measurements with CBCT has the advantage of being non-invasive and is therefore useful in determining the precision of the internal fit.$^{(18-23)}$ this method provide 3D assessment of the internal gap at different points gingival, axial and occlusal in bucco-lingual and mesio-distal sections, so that the internal fit of all ceramic restoration will be assessed from its all aspects enabling to quantify the accuracy of fit of a restoration .All the measurements were performed by one operator to determine the consistency of the obtained data and to avoid statistical variance as much as possible.

The majority of authors agree that marginal discrepancies in the range of $100 \mu \mathrm{m}$ seem to be clinically acceptable with regard to longevity of the restorations. Others claimed that marginal discrepancies exceeding $100 \mu \mathrm{m}$ are clinically inadequate. ${ }^{(18-23)}$ The results obtained in the current study showed that marginal adaptation of the 2 tested groups were within the clinically accepted level.

Comparison between groups using the mean of the 3 successive sections in bucco-lingual section revealed that a higher mean value was recorded in Cerec for each of the gingival, axial and occlusal segments, with no statistically significant difference between groups $(\mathrm{p}=0.138, \mathrm{p}=0.06, \mathrm{p}=0.276$ respectively), (Table 4) while in mesio distal section a higher mean value was recorded in Cerec in the gingival and axial segments, with no significant difference between groups $(\mathrm{p}=0.296, \mathrm{p}=0.568$ respectively). In the occlusal section, a higher 
mean value was recorded in Kavo Everest, with no statistically significant difference between groups $(\mathrm{p}=0.734)$. Comparison of gingival, axial and occlusal segments within the same group in buccolingual section revealed that in Kavo Everest group, a significantly higher mean value was recorded in occlusal segment in comparison to the gingival and axial segments $(\mathrm{p}=0.001)$. In cerec group, a significantly higher mean value was recorded in occlusal segment in comparison to the gingival and axial segments $(\mathrm{p}=0.00)$, (Table 5, Fig.3) while in mesio distal section , in Kavo Everest group, a significantly higher mean value was recorded in occlusal segment in comparison to the gingival and axial segments $(\mathrm{p}=0.00)$. In Cerec group, a significantly higher mean value was recorded in occlusal segment in comparison to the gingival and axial segments $(\mathrm{p}=0.00)$. which indicated that the technique of construction has affected the internal fit of CAD/CAM all-ceramic restorations. So in this study Everest provide a restoration with better adaptation and minimal internal gap compared to Cerec since the 5 axis machine produces samples with more accurate internal fit with improved surface texture and surface finish which leads to increased adaptation of the samples.

This was found in agreement with (Liu and Essig, 2008) ${ }^{(24)}$ and (Giannetopoulous et al, 2010) (25) who stated that the marginal fit average mean value for Everest all-ceramic restorations was less than that recorded for the Cerec system. Also Everest system marginal gap mean values were in agreement with (Okutan et al, 2006). ${ }^{(26)}$ On the other hand, those results were not in agreement with (Kohorst et al, 2009) $^{(27)}$ who found that the mean vertical marginal discrepancy of the Everest system was significantly greater than that of the inLab system. Also, it might be supposed that internal fit in the clinical environment would be larger, as the result of clinical and laboratory inaccuracies, experience of the clinician and also cementation procedures which might increase the marginal gap thickness. ${ }^{(17)}$ thus the null hypothesis was rejected.
Power analysis of the present study showed high values indicating adequate sample size and reliable results, also rejecting the null hypothesis, and proving that different $\mathrm{CAD} / \mathrm{CAM}$ manufacturing techniques have an effect on the internal fit of allceramic restorations

\section{CONCLUSIONS}

The technique of CAD/CAM milling system has affected the internal fit of CAD/CAM all-ceramic restorations.

\section{REFERENCES}

1. Rink S Huts A and Jahn L. Marginal accuracy and fracture strength of conventional and copy milled all-ceramic all ceramic restorations. Int. J. Prosthodont 1995; 8:303-10.

2. Nakamura T, Nonaka M, Maruyama T. In vitro fitting accuracy of copy-milled alumina cores and All-Ceramic All ceramic restorations. Int J Prosthod 2000; 13(3):189-93.

3. Tinschert J, Natt G, Mautsch W, Spiekermann H, Anusavice KJ. Marginal fit of alumina- and zirconia-based fixed partial dentures produced by a CAD-CAM system. Oper Dent 2001;26(4):367-74.

4. Groten MS, Girthofer S, Probster L. Marginal fit consistency of copy-milled all-ceramic all ceramic restorations during fabrication by light and scanning electron microscopic analysis in vitro. J Oral Rehabil 1997; 24(12):871-81.

5. Zidan O, Ferguson G. The retention of complete all ceramic restorations prepared with three different tapers and luted with four different cements. J Prosthet Dent 2003; 89:565-571.

6. Cameron SM, Morris WJ, Keesee SM, Barsky TB, Parker $\mathrm{MH}$. The effect of preparation taper on the retention of cemented cast all ceramic restorations under lateral fatigue loading. J Prosthet Dent. 2006 Jun; 95(6):456-61

7. Goodacre CJ, Campagni WV, Aquilino SA. Tooth preparations for complete all ceramic restorations: an art form based on scientific principles. J Prosthet Dent. 2001 Apr; 85(4):363-76.

8. Chan C, Haraszthy G, Geis-Gerstofer J, Weber H The marginal fit of Cerestore full-ceramic all ceramic restorations - a preliminary report. Quintessence Int 1985;6(3):399-402 
9. Sorensen JA. A standardized method for determination of all ceramic restoration margin fidelity. J Prosthet Dent 1990; 64(1):18-24.

10. Gassino G, Barone Monfrin S, Scanu M, Spina G, Preti G. Marginal adaptation of fixed prosthodontics: A new in vitro 360-degree externalexamination procedure. Int $\mathrm{J}$ Prosthodont 2004;17:218-223.

11. Luthardt RG, Bornemann G, Lemelson S, Walter MH, Hüls A. An innovative method for evaluation of the 3-D internal fit of CAD/CAM all ceramic restorations fabricated after direct optical versus indirect laser scan digitizing. Int J Prosthodont 2004;17:680-685.

12. Coli P, Karlsson S. Fit of a new pressure-sintered zirconium dioxide coping. Int J Prosthodont 2004;17:59-64.

13. Suarez M. J., Gonzaiez De Villaumbrosia P., Pradies G., Lozano J. F.: Comparison of the marginal fit of Procera AllCeram all ceramic restorations with two finish lines. Int. J. Prosthodont 2003; 16(3): 229-32.

14. Gonzalo E, Su?rez MJ, Serrano B, Lozano JF. Comparative analysis of two measurement methods for marginal fit in metal-ceramic and zirconia posterior FPDs. Int $\mathbf{J}$ Prosthodont. 2009 Jul-Aug; 22(4):374-7.

15. Wolfart S, Wegner SM, Al-Halabi A, Kern M. Clinical evaluation of marginal fit of a new experimental allceramic system before and after cementation. Int $\mathrm{J}$ Prosthodont 2003; 16:587-592.

16. Shearer B, Gough MB, Setchell DJ. Influence of marginal configuration and porcelain addition on the fit of In-Ceram all ceramic restorations. Biomateriais 1996; 17(19):1891-5.

17. Beuer F, Neumeier P, Naumann M. Marginal fit of 14-unit zirconia fixed dental prosthesis retainers. J Oral Rehabil. 2009 Feb;36(2):142-9.

18. Riccitiello F,Amato M,Leone R, Spagnuolo $G$ and Sorrentino R: In vitro Evaluation of the Marginal Fit and Internal Adaptation of Zirconia and Lithium Disilicate Single Crowns: Micro-CT Comparison Between Different Manufacturing Procedures.The Open Dentistry Journal, 2018, 12, 160-172
19. Salem NM, Abdel Kader SH, Al Abbassy F, Azer AS. Evaluation of fit accuracy of computer aided design/ computer-aided manufacturing crowns fabricated by three different digital impression techniques using cone-beam computerized tomography. Eur J Prosthodont 2016;4:32-6.

20. Decani O, et al. "Influence of Digital Techniques on Marginal and Internal Adaptation of all Ceramic Implant Supported Crown". EC Dental Science 17.5 (2018): 622637.

21. Thongpun N, Thongbai-on N, Sithiamnuai $P$, Suputtamongkol K. Evaluation of marginal and internal gaps of all-ceramic crowns using X-ray micro-computed tomography. M Dent J 2017; 37: 55-61.

22. Cunali RS, Saab RC, Gisele Maria Correr GM, Leonardo Fernandes da Cunha LF, Ornaghi BP, Ritter AV, Gonzaga CC: Marginal and Internal Adaptation of Zirconia Crowns: A Comparative Study of Assessment Methods.Brazilian Dental Journal (2017) 28(4): 467-473

23. Darwish HA, Morsi TS, El Dimeery AG: Internal fit of lithium disilicate and resin nano-ceramic endocrowns with different preparation designs.Future Dental Journal 3 (2017) 67-72

24. Liu PR, Essig ME.:Panorama of dental CAD/CAM restorative systems.Compend Contin Educ Dent. 2008 Oct;29(8):482, 484, 486-8

25. Giannetopoulos S, van Noort R, Tsitrou E.:Evaluation of the marginal integrity of ceramic copings with different marginal angles using two different CAD/CAM systems.J Dent. 2010 Dec;38(12):980-6.

26. Okutan M1, Heydecke G, Butz F, Strub JR.: Fracture load and marginal fit of shrinkage-free $\mathrm{ZrSiO} 4$ all-ceramic crowns after chewing simulation.J Oral Rehabil. 2006 Nov;33(11):827-32.

27. Kohorst P1, Brinkmann H, Li J, Borchers L, Stiesch M.Marginal accuracy of four-unit zirconia fixed dental prostheses fabricated using different computer-aided design/computer-aided manufacturing systems.Eur J Oral Sci. 2009 Jun;117(3):319-25. 